\title{
Synthesis of pyrrolopyrazinones by construction of the pyrrole ring onto an intact diketopiperazine
}

Susanna K. Maisto, Angela P. Leersnyder, Gwyneth L. Pudner, Jonathan R. Scheerer*

Department of Chemistry, The College of William \& Mary, P. O. Box 8795, Williamsburg, Virginia, 23187

\section{Supporting Information}

${ }^{1} \mathrm{H}$ and ${ }^{13} \mathrm{C}$ NMR Spectra

S2-S18

Spectra acquired in $\mathrm{CDCl}_{3}$ except where noted otherwise. 


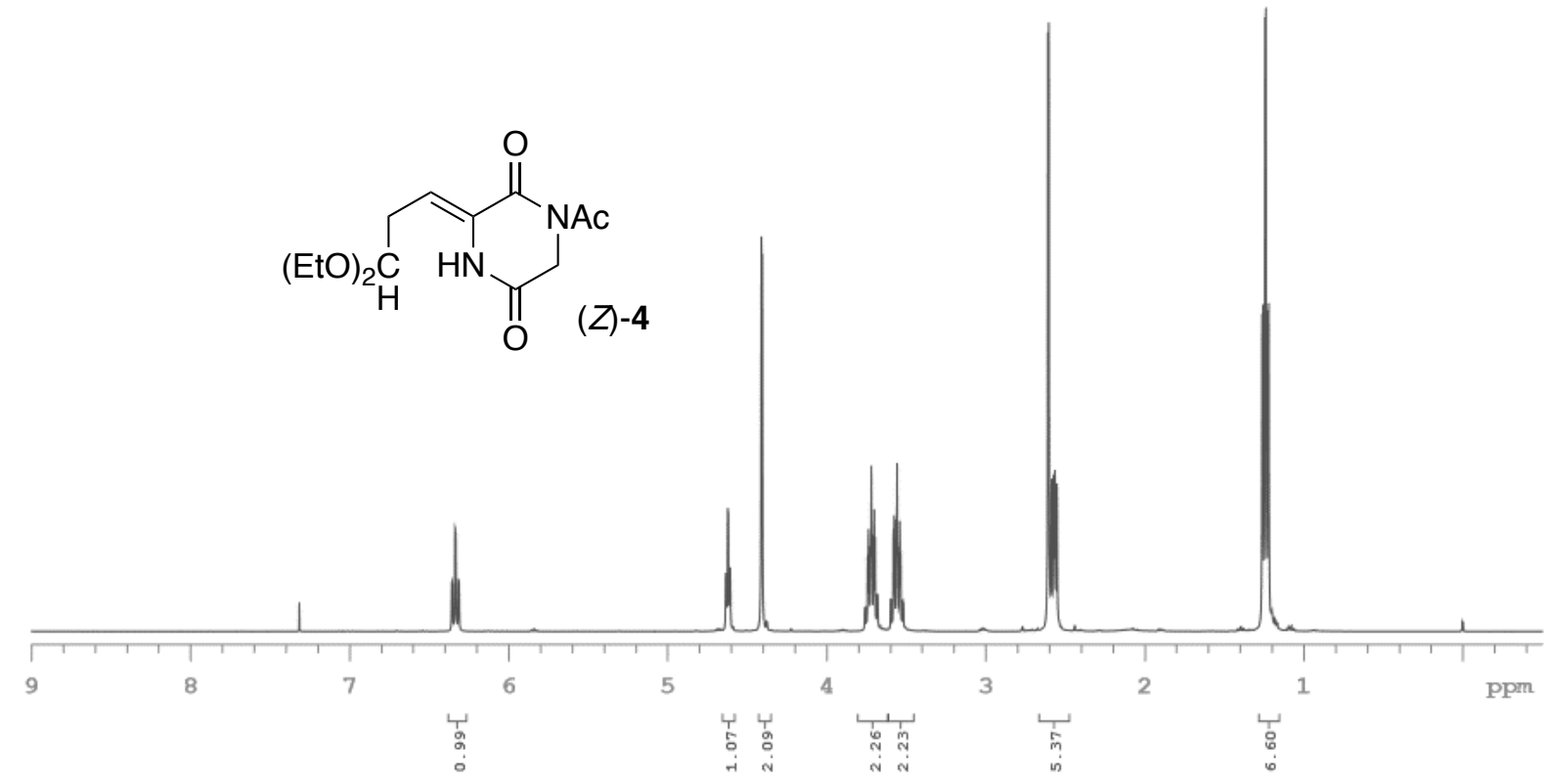

\begin{tabular}{|c|c|c|}
\hline index & frroq(ppm) & Intonsaty \\
\hline 1 & 17238 & 32.6198 \\
\hline 2 & 163.403 & 14.4925 \\
\hline${ }_{3}^{2}$ & $\begin{array}{r}163.4033 \\
163.38\end{array}$ & $\begin{array}{l}14.4925 \\
14.2399\end{array}$ \\
\hline 4 & 160.034 & 16.504 \\
\hline $\begin{array}{l}4 \\
5\end{array}$ & 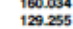 & $\begin{array}{l}16.504 \\
9.64192\end{array}$ \\
\hline 6 & 129.217 & 9.82725 \\
\hline 7 & 117.576 & 18.7914 \\
\hline 8 & 117546 & 17.7174 \\
\hline 9 & 101.723 & 36.1174 \\
\hline 10 & 101.708 & 37.105 \\
\hline 11 & 77.3187 & 29.6358 \\
\hline 12 & & 30.5954 \\
\hline 13 & 76.6813 & 29.7312 \\
\hline 14 & 62.3996 & 65.3227 \\
\hline 15 & 45.8414 & 64.1171 \\
\hline 16 & 31.6509 & 37.715 \\
\hline & 26.9915 & 56.7351 \\
\hline 18 & 15.0851 & 139.5 \\
\hline
\end{tabular}
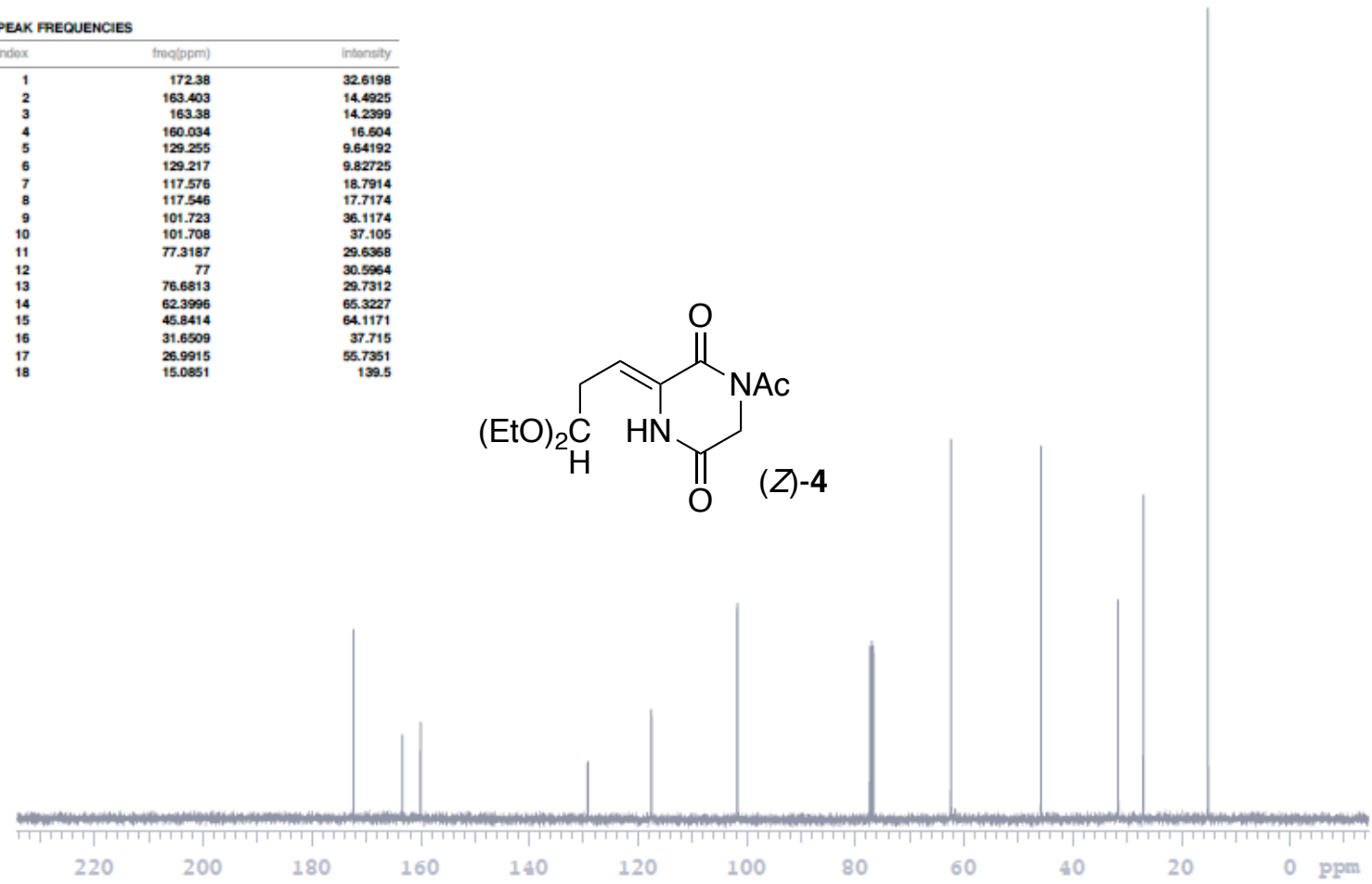


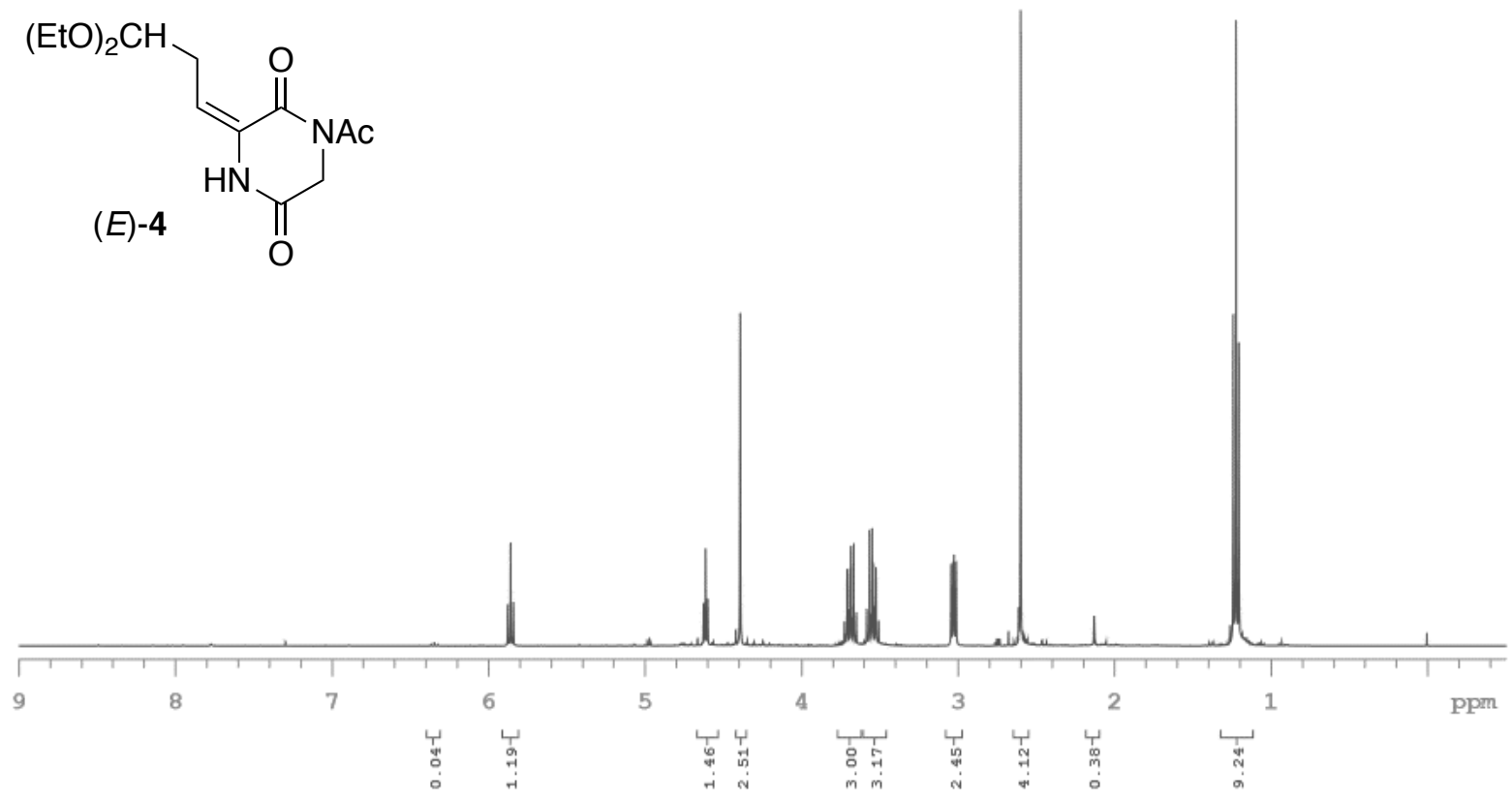

\begin{tabular}{|c|c|c|}
\hline Index & froqppm) & Intonsty \\
\hline 1 & 171.514 & 13.07 \\
\hline 3 & $\begin{array}{l}167.569 \\
1.56897\end{array}$ & 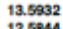 \\
\hline & 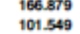 & $\begin{array}{r}12.5844 \\
5.8181\end{array}$ \\
\hline 5 & 101.473 & $\begin{array}{l}14.2181 \\
\end{array}$ \\
\hline 6 & 83.1315 & 17.3919 \\
\hline 7 & $\begin{array}{l}7.3187 \\
\pi .2049\end{array}$ & $\begin{array}{l}1368488 \\
6558723\end{array}$ \\
\hline & & \\
\hline 10 & 76.6813 & 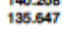 \\
\hline 11 & 720057 & 11.563 \\
\hline 12 & 63.0219 & $\begin{array}{l}17.9575 \\
0.95001\end{array}$ \\
\hline & $\begin{array}{l}62.0657 \\
68120305\end{array}$ & 9.66091 \\
\hline 15 & 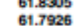 & $\begin{array}{l}\begin{array}{l}15.4007 \\
14.3491\end{array}\end{array}$ \\
\hline 16 & 46,7065 & $\begin{array}{l}14.85981 \\
10.858\end{array}$ \\
\hline & 34.9595 & 10.7205 \\
\hline 18 & 27.2419 & 18.7786 \\
\hline 19 & $\begin{array}{l}27.0977 \\
1.5214\end{array}$ & 10.3979 \\
\hline & $\begin{array}{l}15.12141 \\
15.1382\end{array}$ & 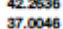 \\
\hline${ }_{22}$ & $\begin{array}{l}15.0772 \\
1.5875\end{array}$ & $\begin{array}{l}37.046 \\
13.8731\end{array}$ \\
\hline
\end{tabular}
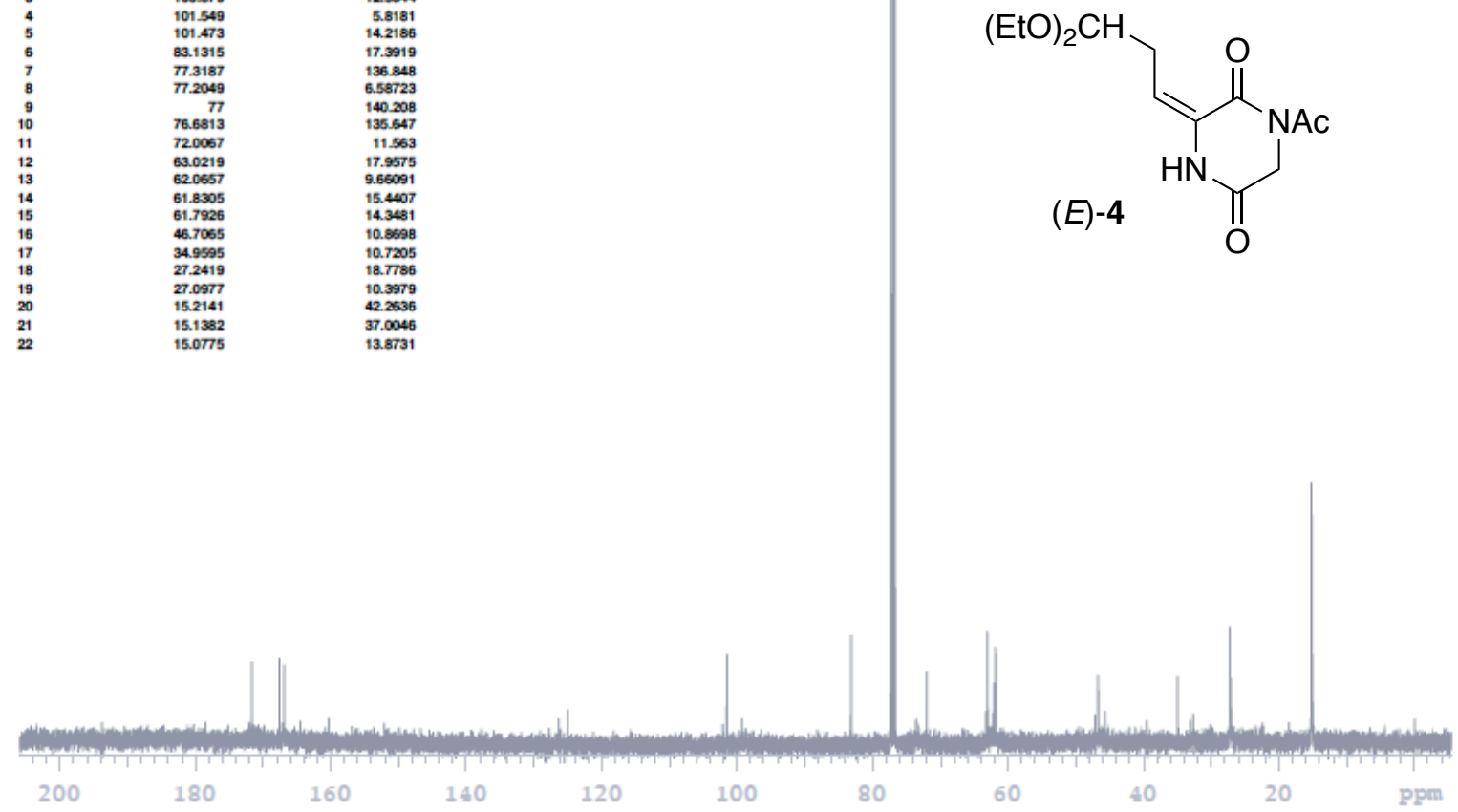
<smiles>C[14C](=O)c1ccccc1</smiles>
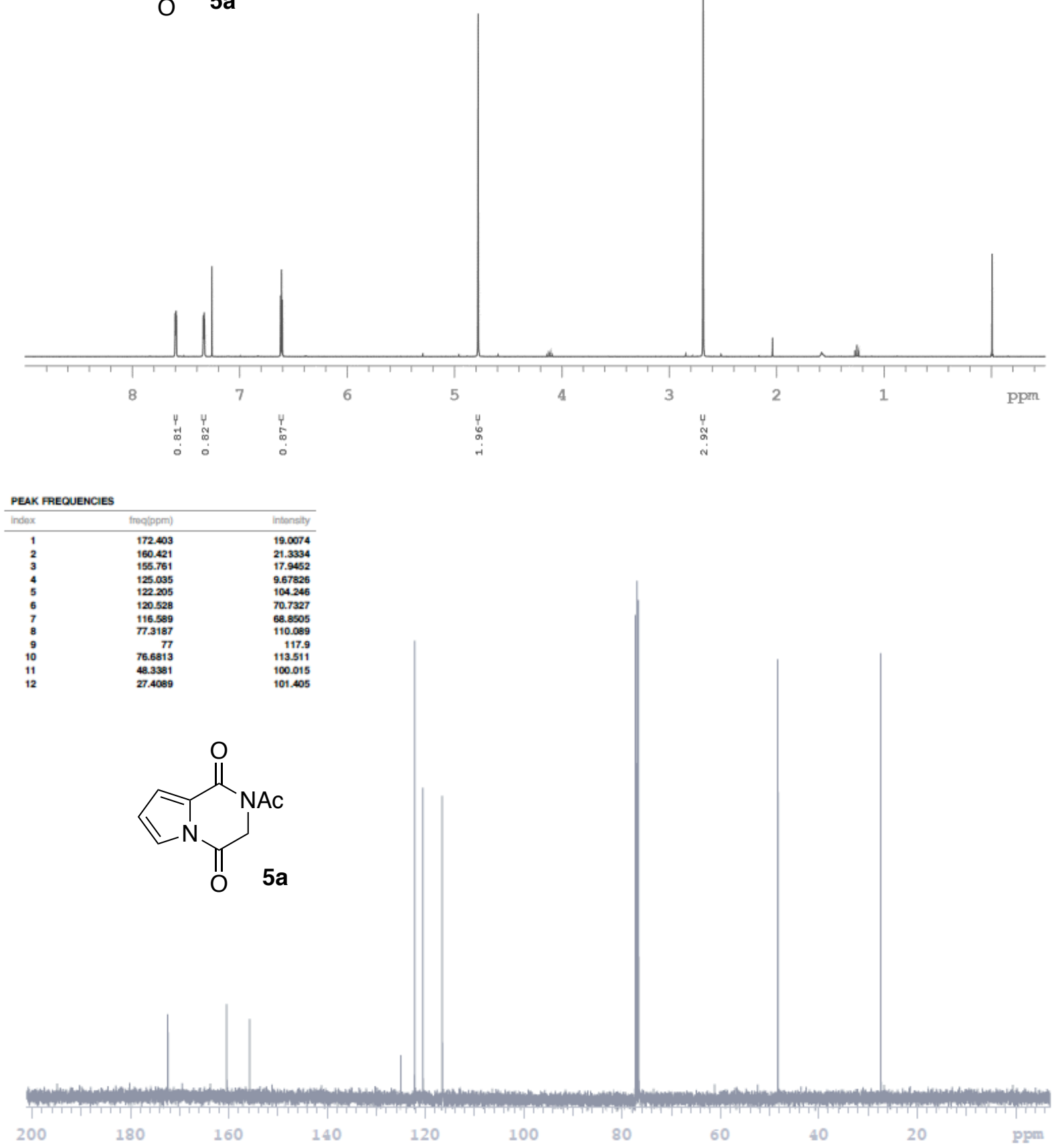
<smiles>CC1(C/C=C2\NC(=O)CN(C(C)(C)C)C2=O)OCCO1</smiles>
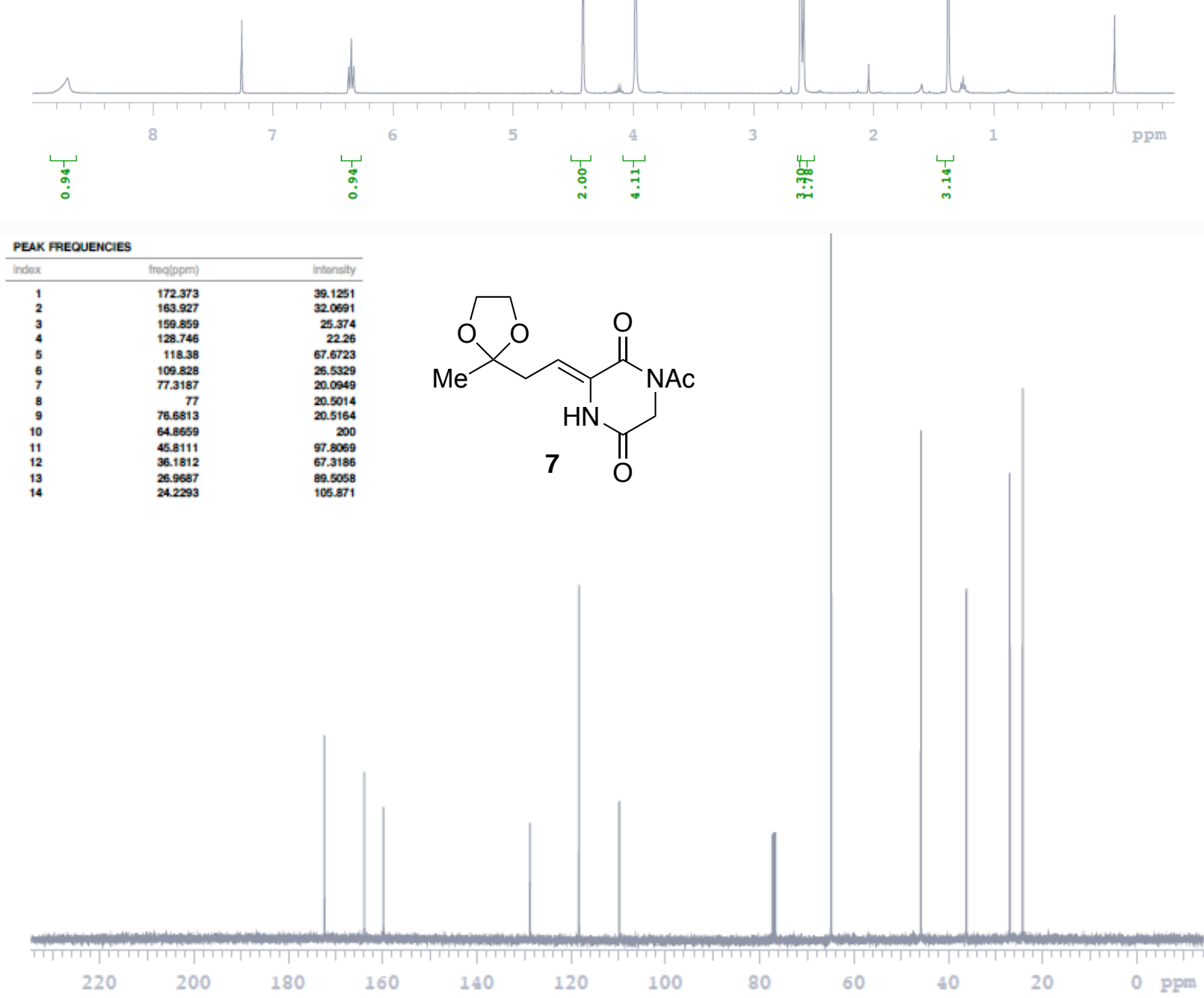
<smiles>Cc1ccc2n1C(=O)CN(C(C)(C)C)C2=O</smiles>
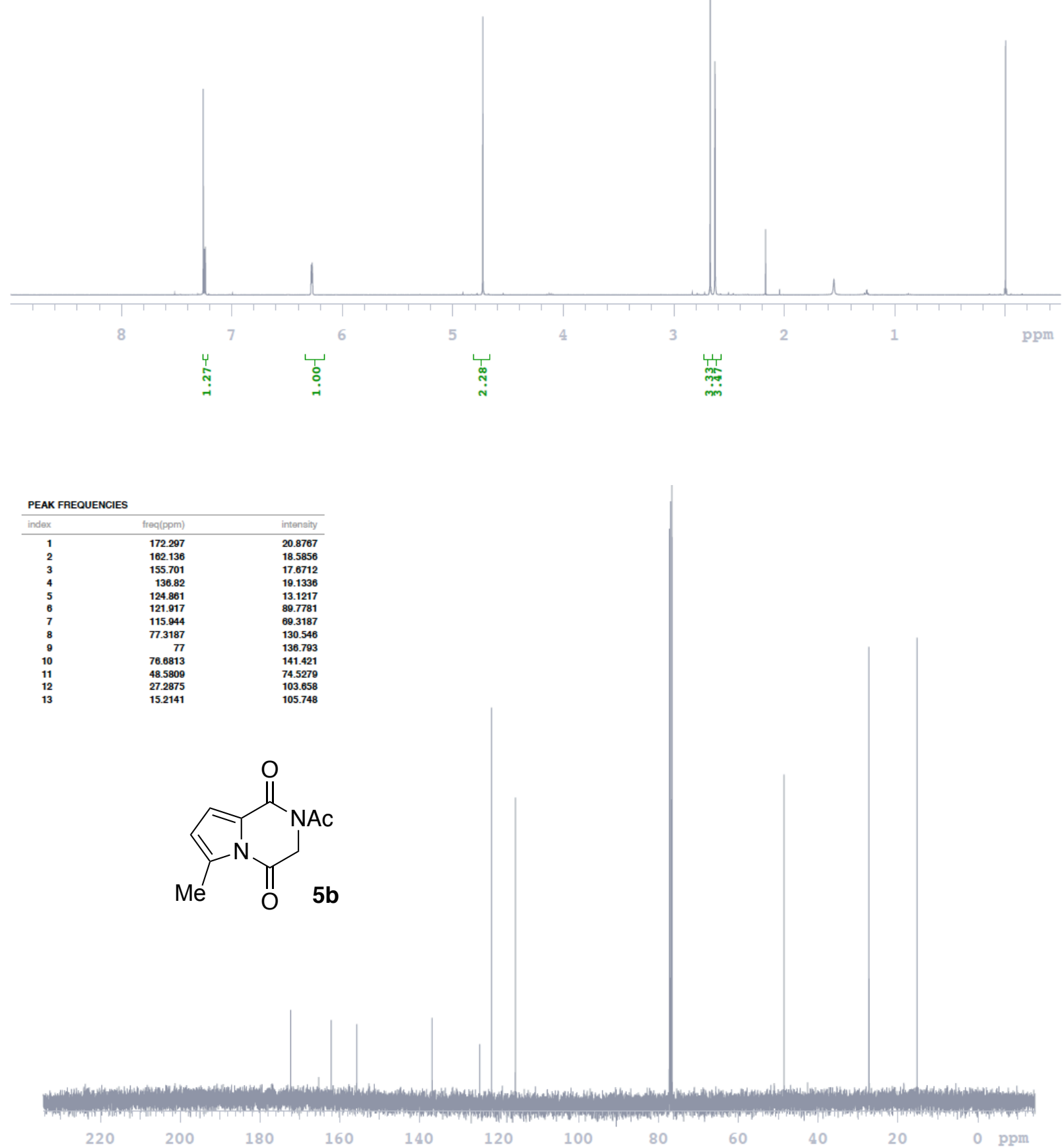

$160 \quad 140$

120

100

80

60

40

20 

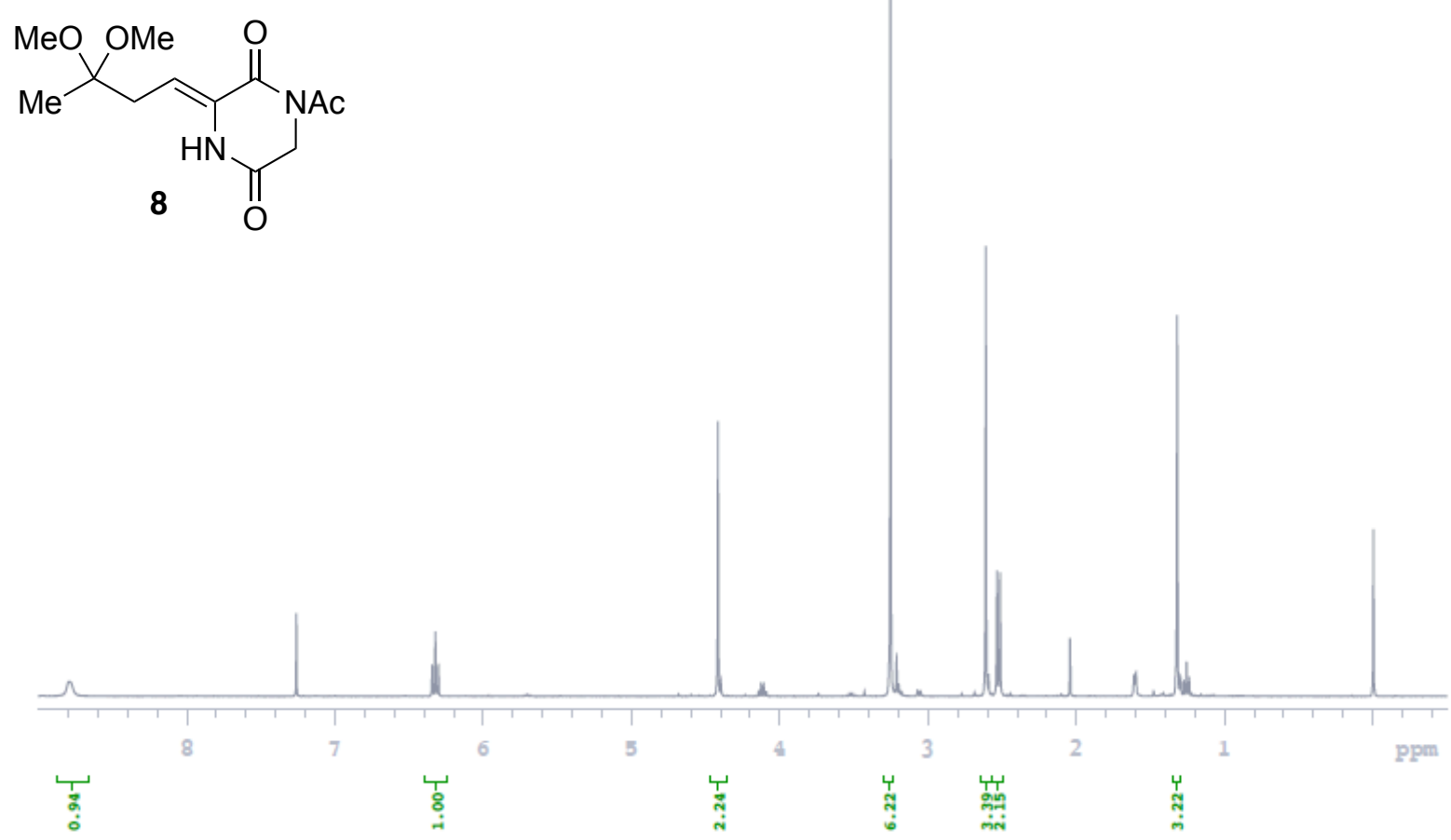

\begin{tabular}{|c|c|c|}
\hline Index & froq(ppm) & Intonsity \\
\hline 1 & 172.471 & 44.77 \\
\hline 2 & 163.76 & 42.4758 \\
\hline 3 & 160.003 & 37.5075 \\
\hline 4 & 128.731 & 34.2528 \\
\hline 5 & 118.433 & 69.4553 \\
\hline 6 & 102.088 & 38.2353 \\
\hline 7 & 77.3187 & 94.4678 \\
\hline 8 & 77 & 95.1829 \\
\hline 9 & 76.6813 & 99.0682 \\
\hline 10 & 48.5354 & 237.841 \\
\hline 11 & 45.85666 & 117.004 \\
\hline 12 & 34.5573 & \\
\hline 13 & 27.0446 & \\
\hline 14 & 21.6254 & 138.6 \\
\hline
\end{tabular}




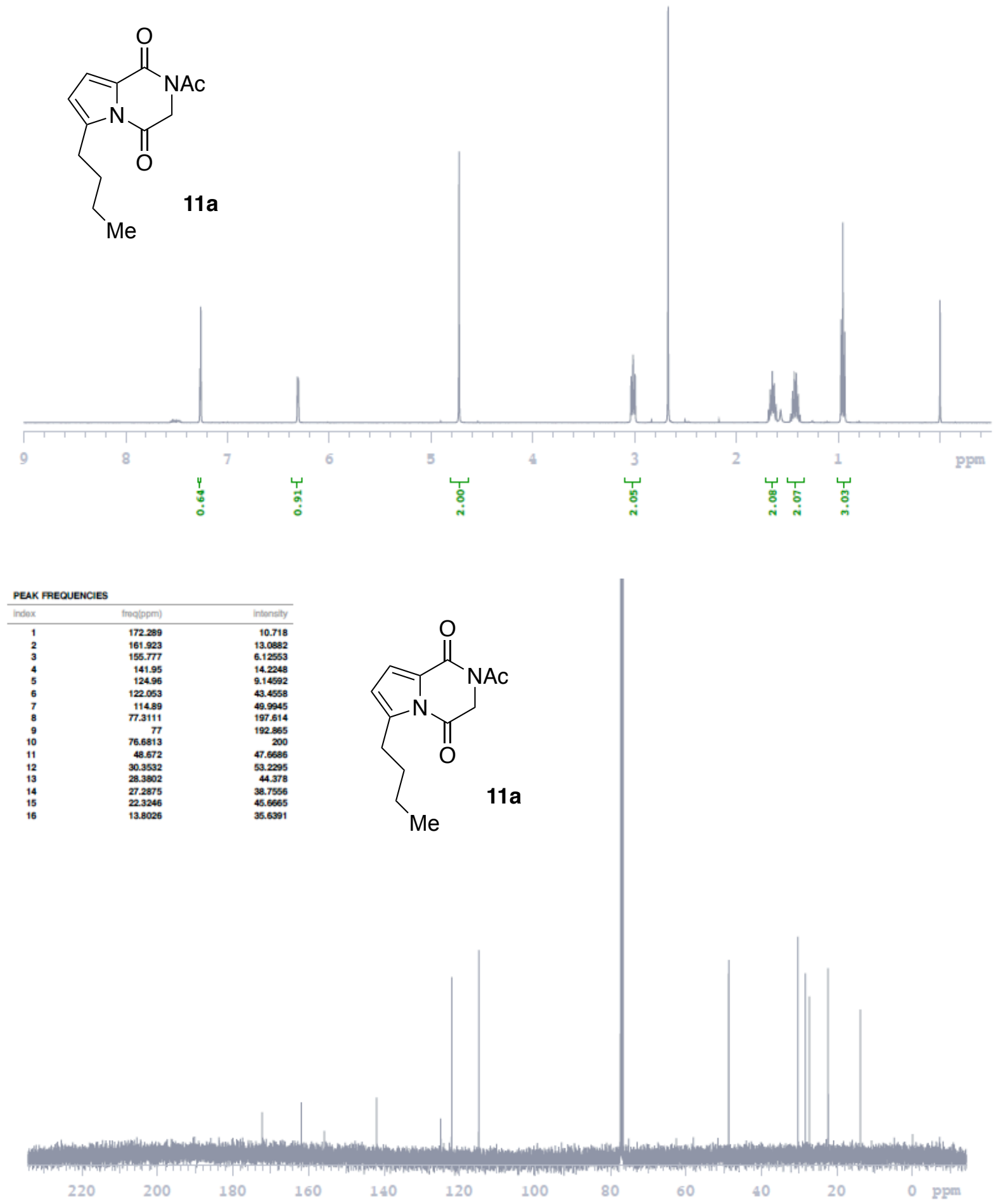


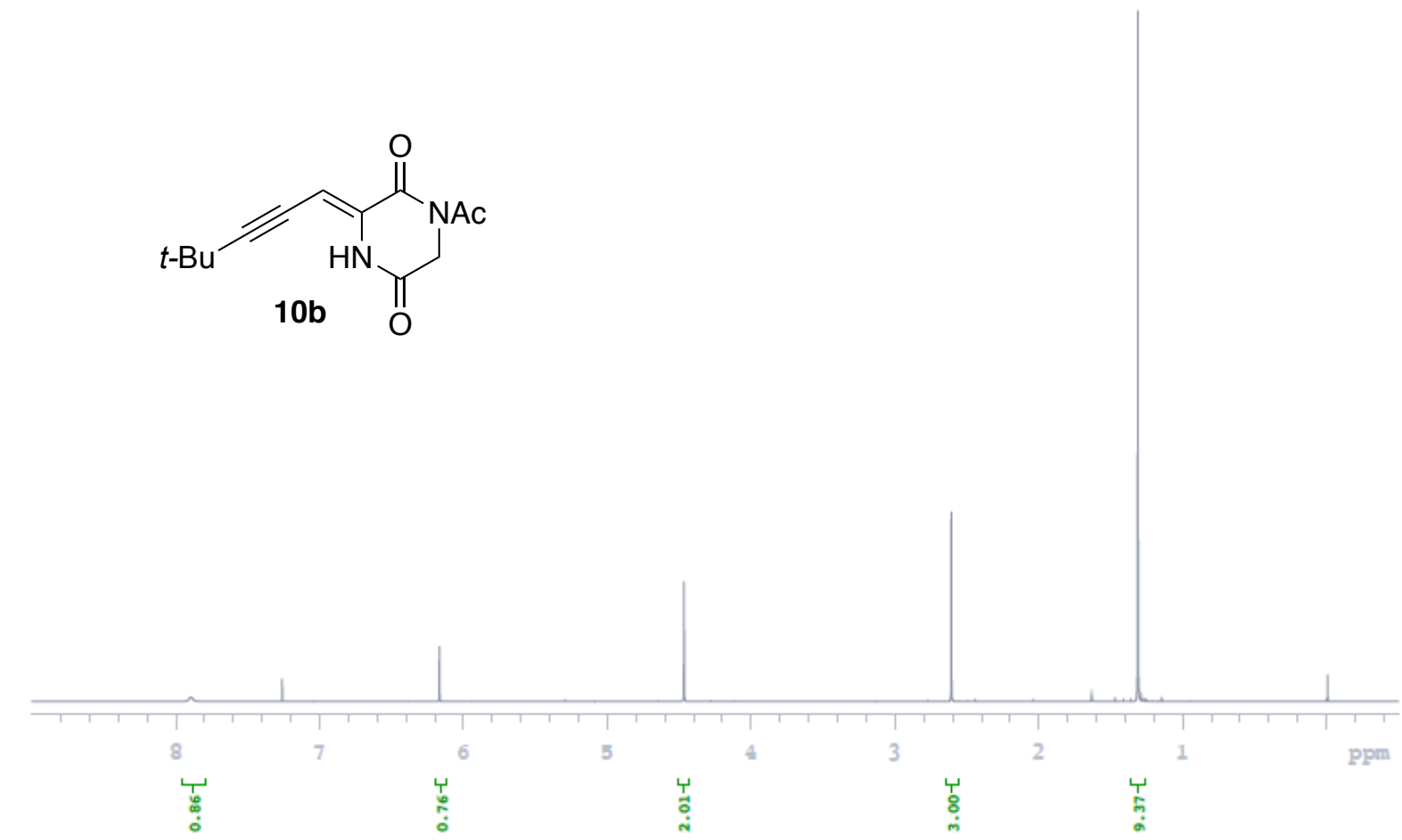

\begin{tabular}{|c|c|c|}
\hline Index $x$ & frmofppm) & Intonsity \\
\hline 1 & 172.289 & 20.7859 \\
\hline 2 & 161.946 & 24.7113 \\
\hline 3 & 158.524 & 14.8569 \\
\hline 4 & 133.231 & 15.7926 \\
\hline 5 & 116.104 & 23.8038 \\
\hline 6 & 100.722 & 59.3745 \\
\hline 7 & 77.3187 & 123.497 \\
\hline 8 & 77 & 124.819 \\
\hline 9 & 76.6813 & 115.979 \\
\hline 10 & 72.8794 & 25.7344 \\
\hline 11 & 46.5017 & 64.9007 \\
\hline 12 & 30.7099 & 200 \\
\hline 13 & 28.8735 & 58.6146 \\
\hline 14 & 27.2258 & 75.7494 \\
\hline
\end{tabular}
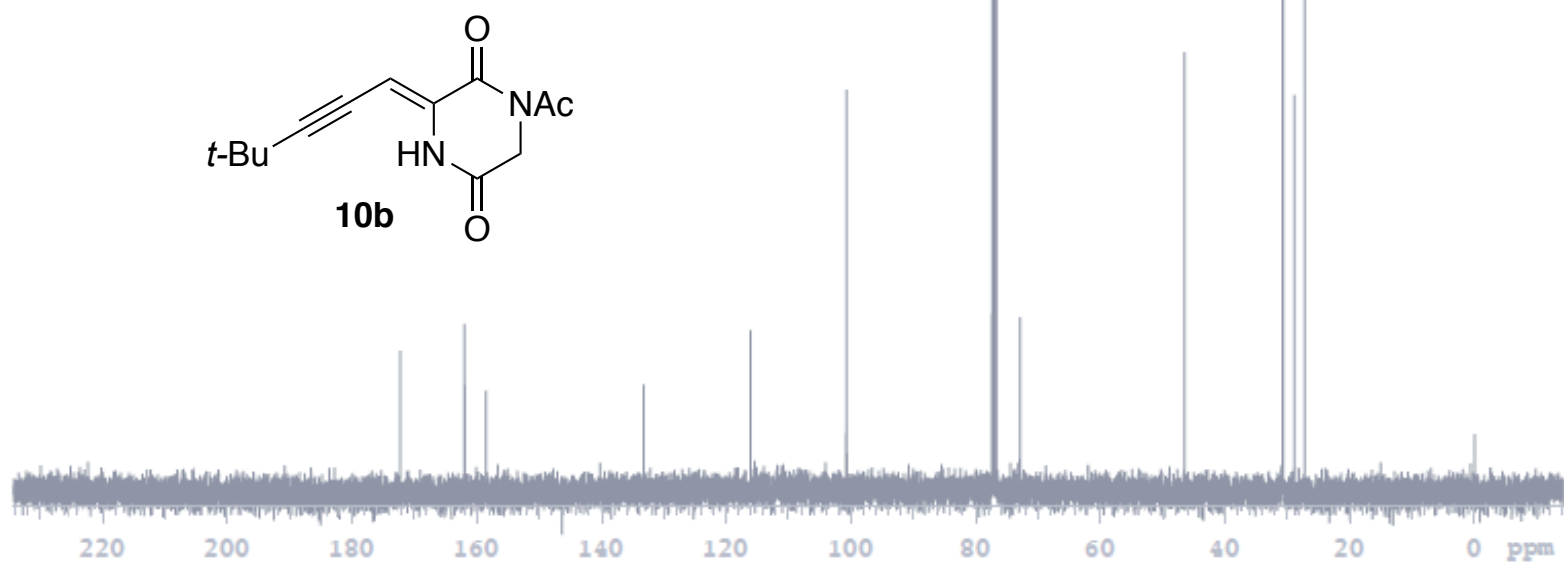


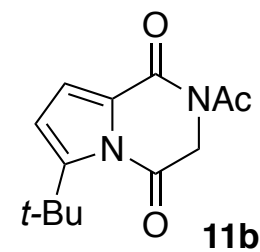

\begin{tabular}{|c|c|c|}
\hline Index & froq(ppm) & Intonsity \\
\hline 1 & 172.039 & 19.4103 \\
\hline 2 & 160.982 & 25.3487 \\
\hline 3 & 155.815 & 15.6577 \\
\hline 4 & 150.516 & 18.6085 \\
\hline 5 & 127.175 & 13.4467 \\
\hline 6 & 122.051 & 55.6311 \\
\hline 7 & 114.419 & 73.8155 \\
\hline 8 & 77.3187 & 177.354 \\
\hline 9 & 77 & 182.751 \\
\hline 10 & 76.6813 & 177.753 \\
\hline 11 & 48.9223 & 75.8345 \\
\hline 12 & 33.7301 & 52.7006 \\
\hline 13 & 29.1846 & 282.843 \\
\hline 14 & 27.1888 & 73.0587 \\
\hline
\end{tabular}
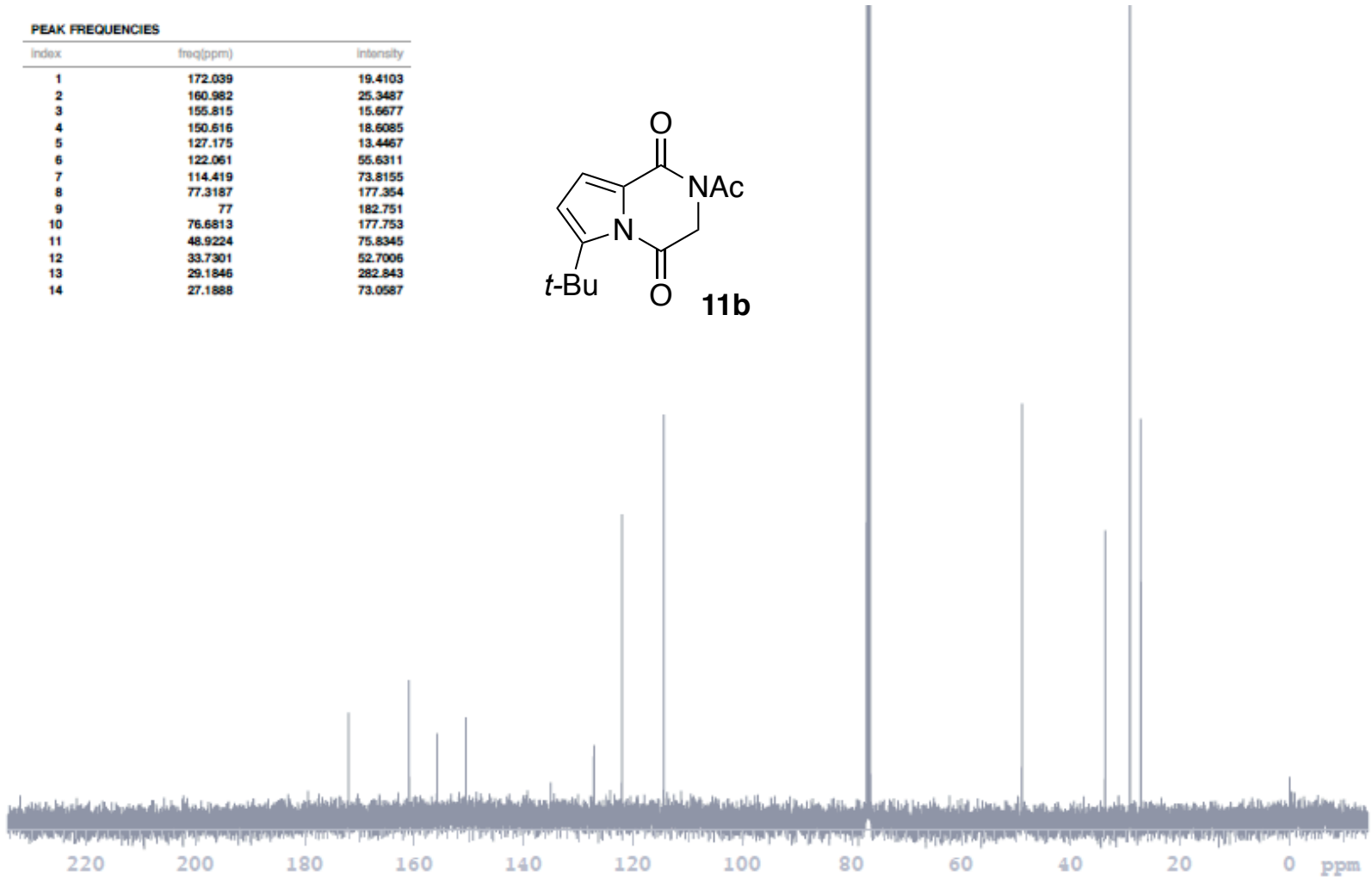

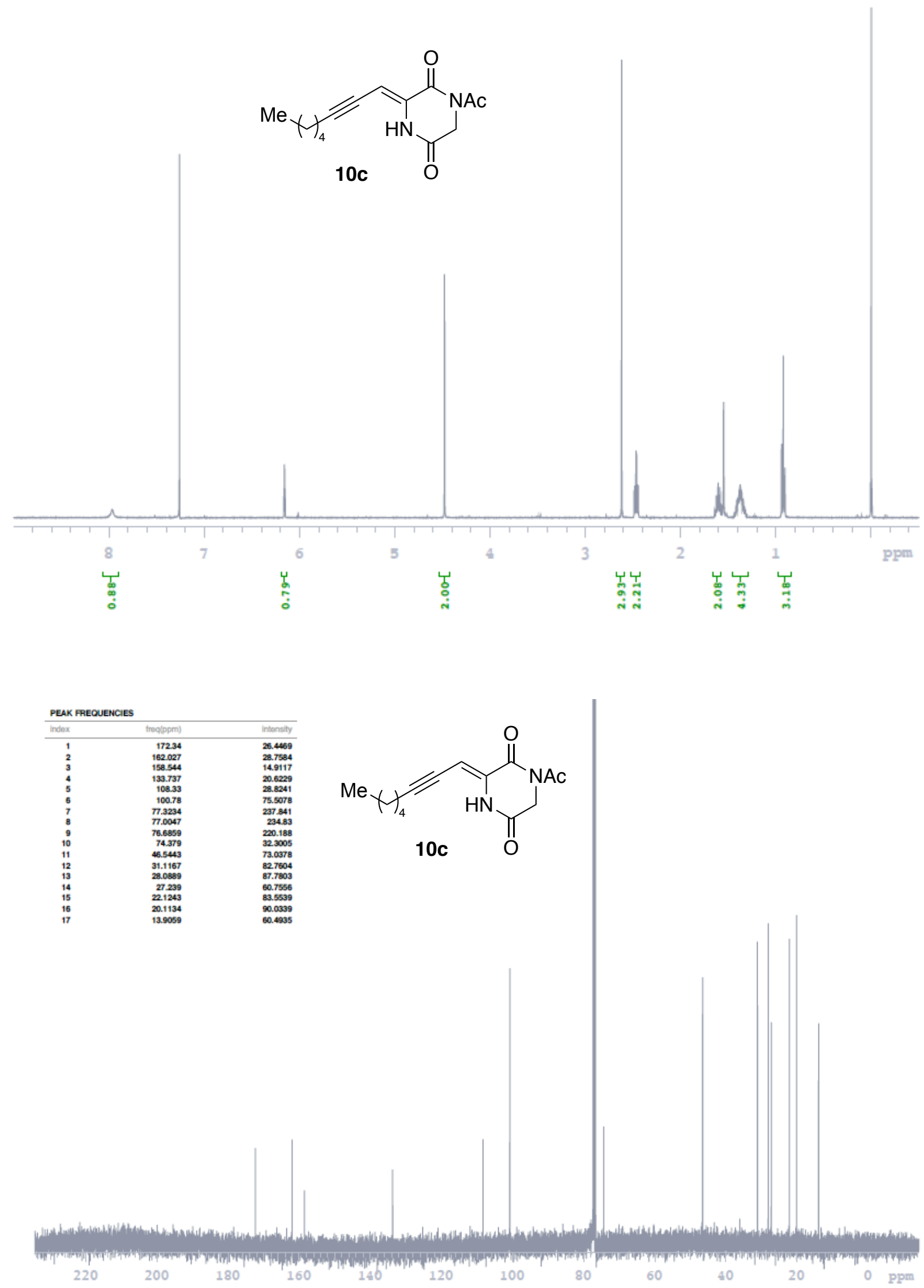

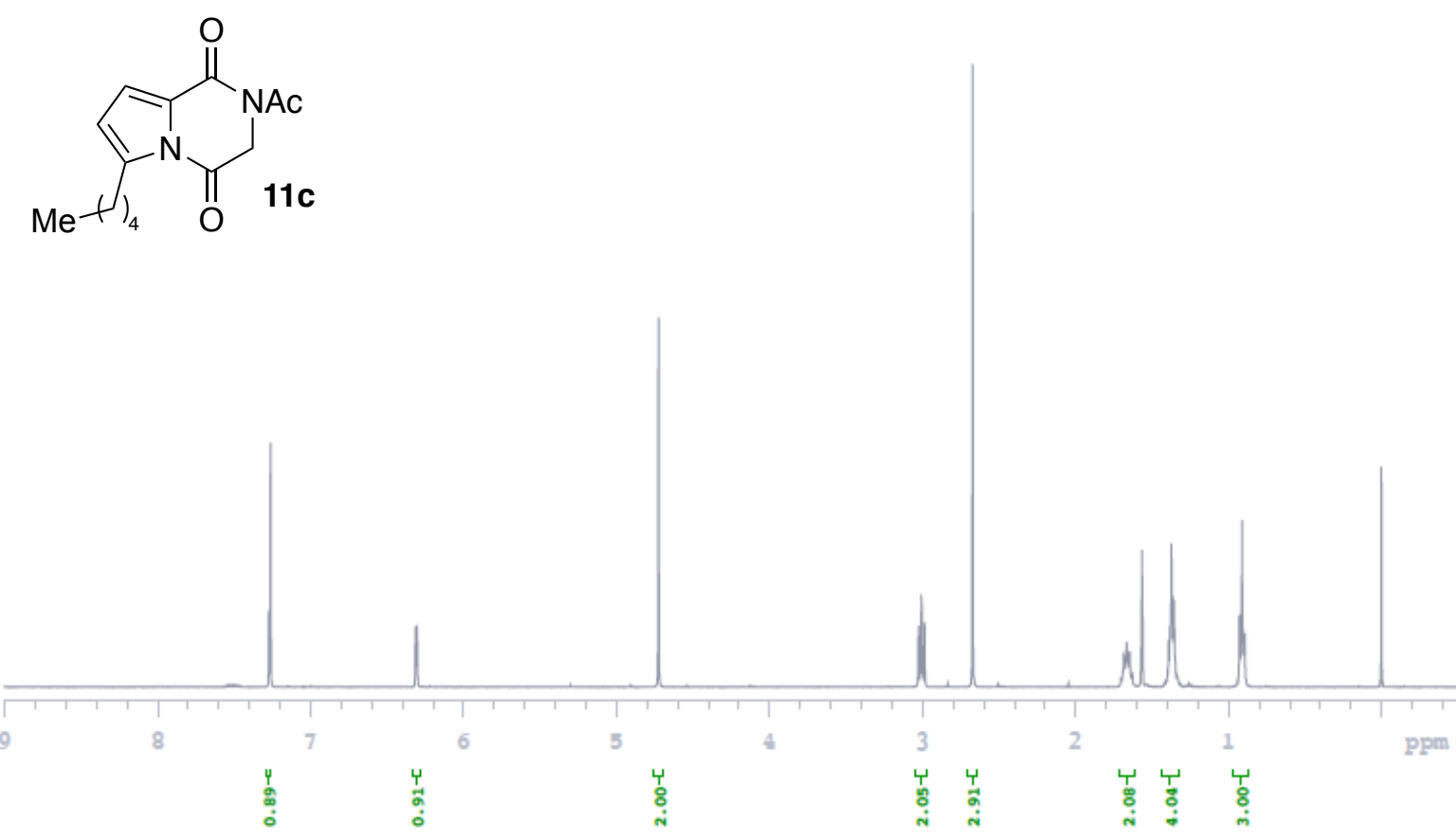

\begin{tabular}{|c|c|c|}
\hline Index $x$ & frroqfppm) & \\
\hline 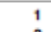 & 172274 & \\
\hline${ }_{3}^{2}$ & $\begin{array}{l}161.908 \\
15557.796\end{array}$ & \\
\hline 4 & 141.966 & \\
\hline 7 & 114.582 & \\
\hline 8 & 7.3111 & \\
\hline $\begin{array}{c}9 \\
10\end{array}$ & 76.6817 & \\
\hline 11 & 48.6588 & \\
\hline $\begin{array}{l}12 \\
13 \\
13\end{array}$ & $\begin{array}{l}31.3701 \\
286079\end{array}$ & \\
\hline 14 & $\begin{array}{l}27.9249 \\
2777279\end{array}$ & \\
\hline $\begin{array}{l}16 \\
16\end{array}$ & 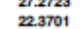 & \\
\hline 17 & 13.9992 & \\
\hline
\end{tabular}<smiles>CCCCc1ccc2n1C(=O)CN(C(C)(C)C)C2=O</smiles>

$\mathrm{Me}+)_{4} \quad$ 11c

236.375

7.5066

11.451
102.254

105.553
84.0596

78.2491

$\mathrm{Me}^{-()_{4}} \mathrm{O}$ 


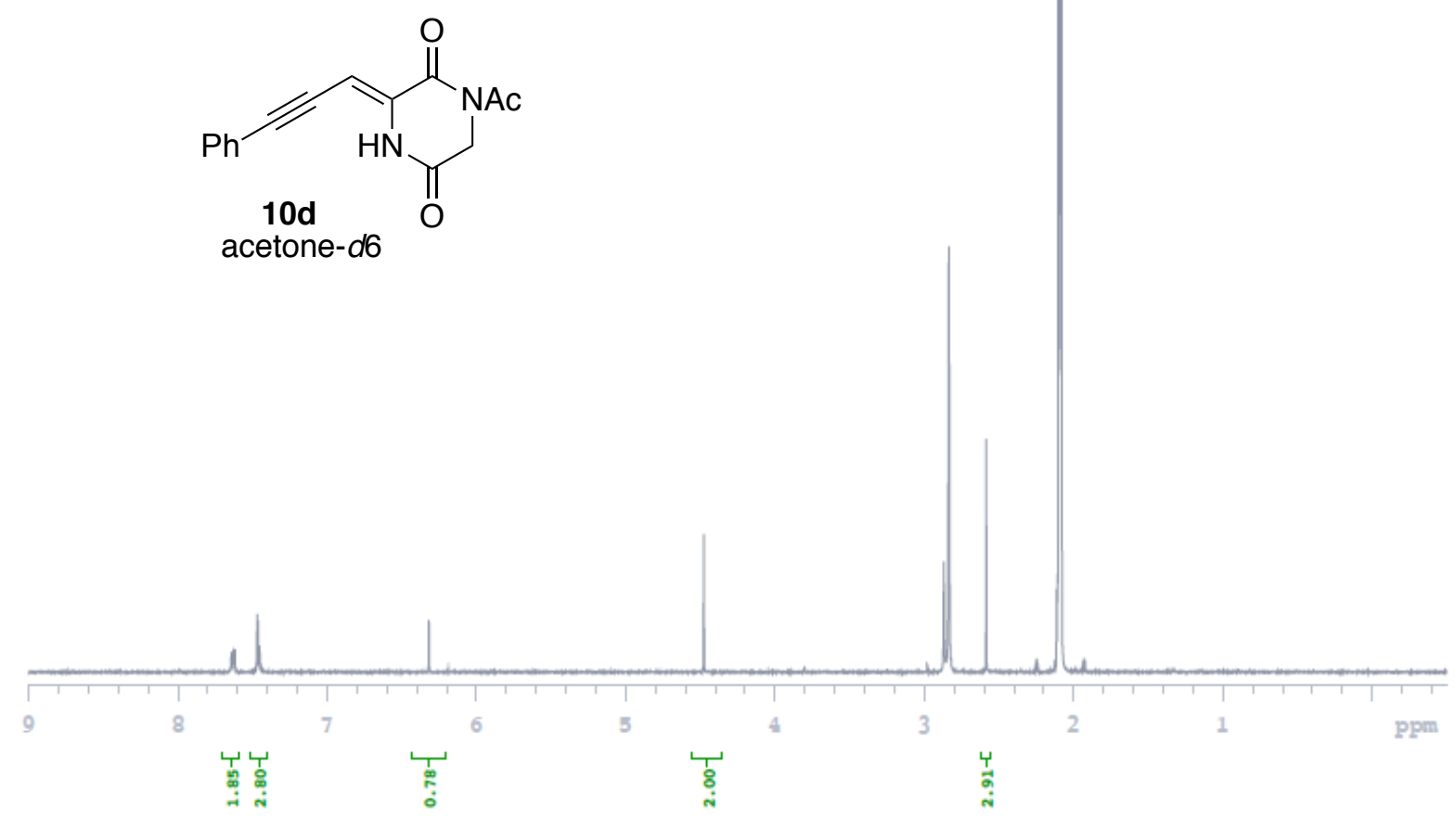

\begin{tabular}{|c|c|c|}
\hline Index & froq(ppm) & Intonsty \\
\hline 1 & 172 & 20.8956 \\
\hline 2 & 163.539 & 27.6288 \\
\hline 3 & 159.297 & $\begin{array}{l}21.706088 \\
19.9055\end{array}$ \\
\hline 4 & 136.205 & 23.5825 \\
\hline 5 & 131.827 & 97.6932 \\
\hline 6 & 129.277 & 32.2743 \\
\hline 7 & 128.579 & 88.6587 \\
\hline 8 & 122.356 & 22.4214 \\
\hline 9 & 102.376 & 19.0055 \\
\hline 10 & 96.2051 & 37.7325 \\
\hline 11 & 84.4743 & 16.176 \\
\hline 12 & $\begin{array}{l}86.5773 \\
\end{array}$ & $\begin{array}{r}16.176 \\
42.2529\end{array}$ \\
\hline 13 & 40.1498 & 106.723 \\
\hline 14 & 39.9374 & 326.517 \\
\hline $\begin{array}{l}14 \\
15\end{array}$ & 39.7325 & 658.815 \\
\hline 16 & 39.52 & 799.999 \\
\hline 17 & 39.3075 & 657.856 \\
\hline 18 & 39.1026 & 342.799 \\
\hline 19 & 38.8902 & 106.702 \\
\hline 20 & 27.0217 & \\
\hline
\end{tabular}

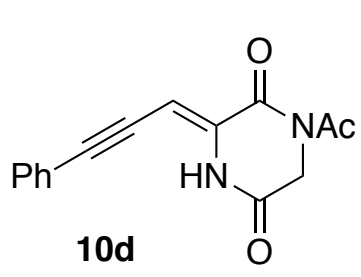

DMSO-d6







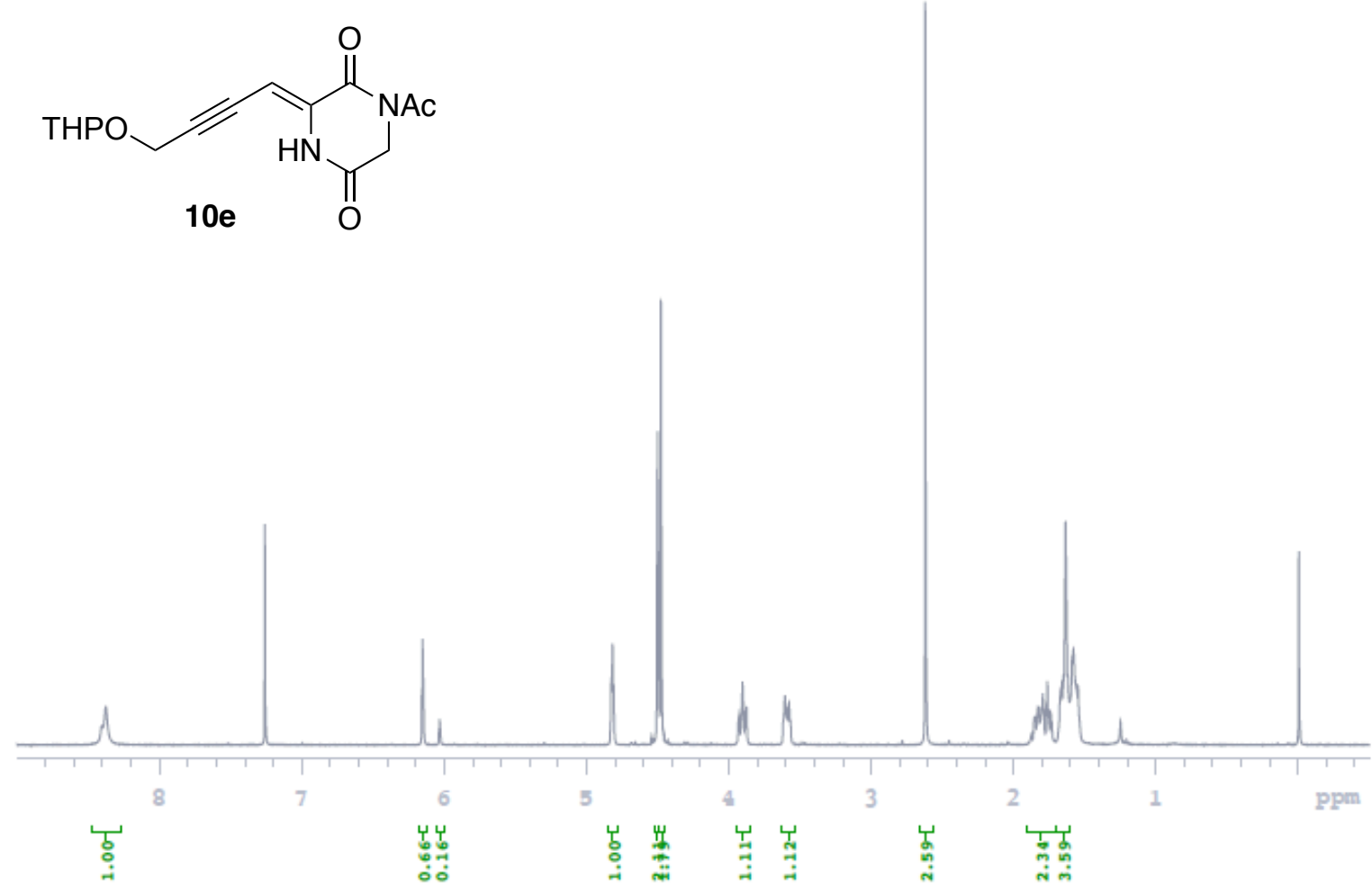

\begin{tabular}{|c|c|c|}
\hline index & froq(ppm) & intensily \\
\hline 1 & 172.244 & 16.6228 \\
\hline & 161.951 & 28.0595 \\
\hline 3 & 158.228 & 19.7966 \\
\hline 4 & 136.447 & 19.7103 \\
\hline 5 & 101.739 & 25.8506 \\
\hline 6 & 98.5818 & 59.8708 \\
\hline 7 & 98.3162 & 58.1669 \\
\hline 8 & 98.2555 & 10.0078 \\
\hline & 96.5708 & 9.15395 \\
\hline 10 & 79.2766 & 17.8501 \\
\hline 11 & 77.3187 & 369.796 \\
\hline 12 & 77.1973 & 13.9881 \\
\hline 13 & 77 & 399.594 \\
\hline 14 & 76.6813 & 400 \\
\hline 15 & 62.2782 & 58.6227 \\
\hline 16 & 55. 5017 & 16.1302 \\
\hline 17 & 56.4789 & 69.1497 \\
\hline 18 & 46.5548 & 56.4193 \\
\hline & 30.3305 & 60.4399 \\
\hline 20 & 27.2799 & 53.8529 \\
\hline 21 & 25.193 & 75.1272 \\
\hline 22 & 19.0235 & 78.0973 \\
\hline 23 & -0.0237003 & 9.70227 \\
\hline
\end{tabular}

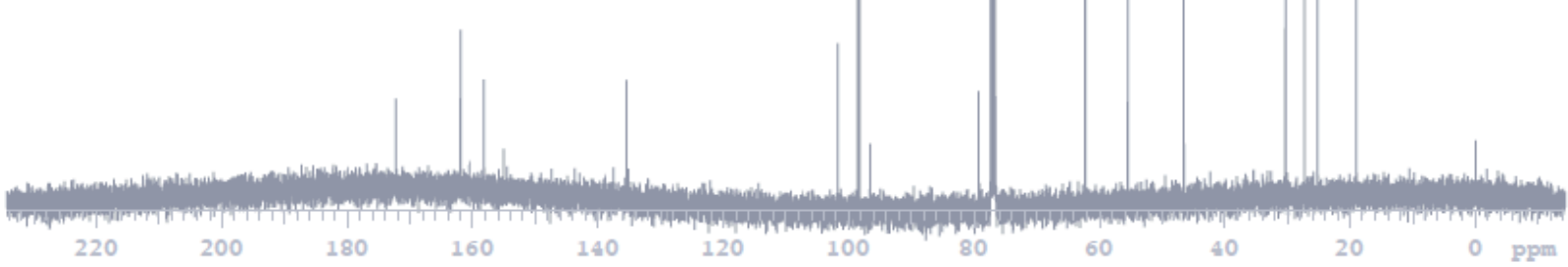



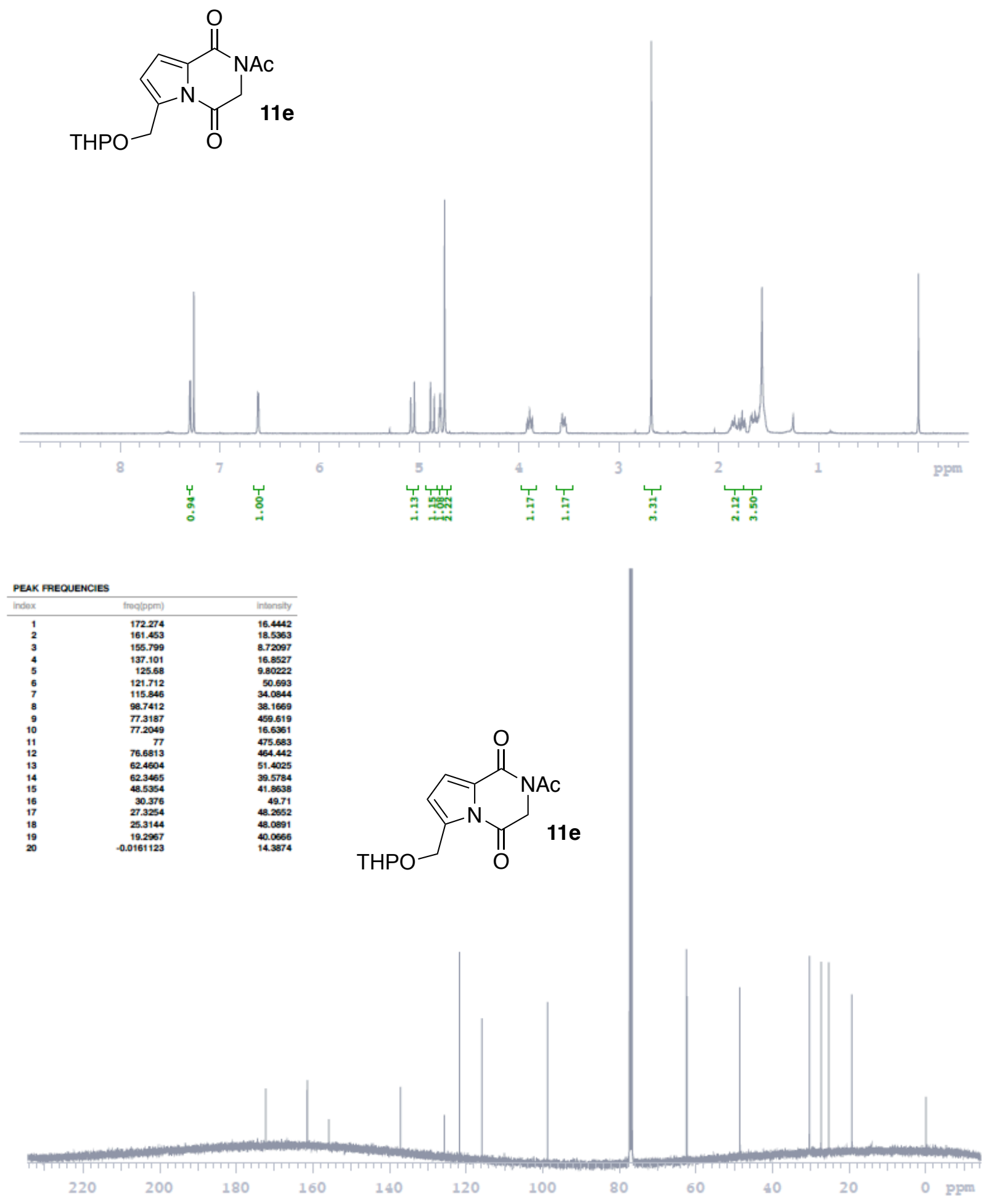

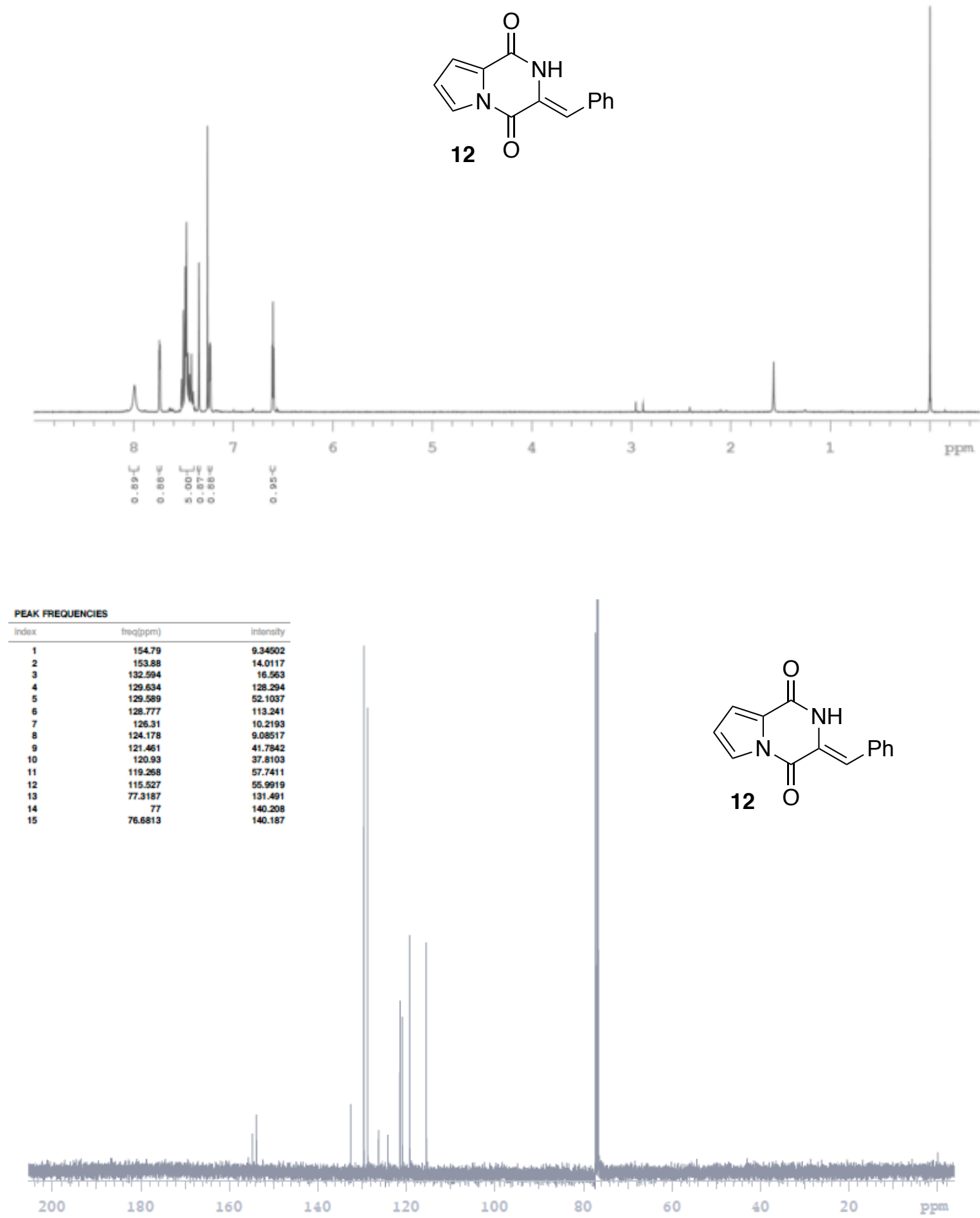